\title{
Como pensar o Voleibol de Praia sociologicamente ${ }^{1}$
}

\author{
Gilmar Francisco Afonso ${ }^{1,2}$ \\ Wanderlei Marchi Júnior 1,2 \\ ${ }^{1}$ Universidade Federal do Paraná, Centro de Pesquisa em Esporte, Lazer e Sociedade \\ (CEPELS), Curitiba, Brasil \\ ${ }^{2}$ Asociación Latinoamericana de Estudios Socioculturales del Deporte (ALESDE)
}

\begin{abstract}
Resumo: Este artigo trata de uma análise sociológica da história do Voleibol de Praia. Aqui procuramos responder: por que o desenvolvimento internacional da modalidade ocorreu no Brasil e não nos EUA? Como hipótese apresentamos que a estrutura do campo Voleibol de Praia vem sendo determinada pela disputa de duas instituições, a Federação Internacional de Voleibol (FIVB) e a Association of Volleyball Professionals (AVP). Os objetivos foram investigar por que o Brasil foi o local onde o Voleibol de Praia se transformou em show business internacional e analisar as configurações entre os agentes/estruturas que compõem o campo. O recorte compreendeu o intervalo de 1985 a 2004. Como referencial teórico metodológico de análise, buscamos na teoria dos campos de Pierre Bourdieu o instrumental capaz de explicitar as relações que se estabelecem no contexto socioeconômico contemporâneo, aplicando-o na leitura do desenvolvimento do Voleibol de Praia. Constatamos que a FIVB assumiu o controle do campo e o Brasil passou a ser uma estrutura estruturante da modalidade.
\end{abstract}

Palavras-chave: Voleibol de praia. Profissionalização. Mercantilização. Espetacularização.

\section{How to think Beach Volleyball sociologicaly}

Abstract: This study carried out a sociological analysis of the history of Beach Volleyball. The problem was: why has the development of Beach Volleyball as an international sport occurred in Brazil rather than in the USA? The hypothesis proposed that the framework of the field of Beach Volleyball has been defined by the dispute between two institutions, the Fèdèration Internationale de Volleyball (FIVB) and the Association of Volleyball Professionals (AVP). The outlined goals were to investigate why Brazil came to be where Beach Volleyball was transformed into International Show Business and analyze the structure of the interdependent relationships among the sub components that make up the field. The proposed period included the years 1985 to 2004. The instrument capable of expounding the relationships that are established in the contemporary socioeconomic context was found in the 'theory of fields' of Pierre Bourdieu, which was applied to the material comprehending the development of Beach Volleyball. The historical material analyzed confirmed that the FIVB took control of the sport, which therefore defined Brazil internationally as the reference for Beach Volleyball.

Keywords: Beach volleyball. Professionalization. Commodification. Sports spectacle.

\section{Introdução}

O Voleibol de Praia (VP) nasceu nos Estados Unidos da América do Norte (EUA) no início do século $X X$ e desenvolveu-se de acordo com os princípios da sociedade norte-americana. Em pouco mais de 70 anos, a modalidade estruturouse e firmou-se dentro do campo esportivo mundial. Nesse ínterim, de simples diversão familiar e de atividade de lazer passou a posicionar-se como um lucrativo business de verão nas mais famosas praias do mundo.

O VP é uma modalidade derivada do Voleibol, nesse caso, podemos visualizar uma origem

\footnotetext{
1 Trabalho derivado de dissertação de mestrado de Gilmar Francisco Afonso, Curso de Pós-Graduação em Educação Física, Setor de Ciências Biológicas, Universidade Federal do Paraná. 2004.
}

comum. Para analisar a história do VP, é importante ilustrar as suas "raízes" originais.

O Voleibol foi um esporte inventado nos EUA com características específicas para atender as necessidades de um determinado grupo social, em outras palavras, constituiu-se como um esporte moderno portador de um conjunto de características e instituições distintas dos esportes de origem européia. Esses evoluíram de práticas culturais, dos jogos ancestrais e dos passatempos, já o Voleibol foi moldado pelas leis e estruturas que estabeleciam as bases da sociedade norte-americana (MARCHI JÚNIOR, 2004).

Nos EUA, os esportes modernos desenvolveram-se entre a elite econômica, primeiramente, nos clubes, associações e, posteriormente, na constituição das equipes 
escolares competitivas. Neste contexto, firmou-se uma nova burguesia que superava as restrições ideológicas e religiosas impostas ao lucro, não perdendo de vista os princípios do utilitarismo, da racionalidade, do nacionalismo e da iminente sociedade de consumo de massa (MARCHI JÚNIOR, 2004).

Outro fator importante dentro do processo de desenvolvimento dos esportes modernos, nos EUA, foi a religião. A ética religiosa protestante via o homem como centro do mundo. Essa individualização passou a fundamentar as ações em busca de prestígio pessoal. Pecado era desperdiçar tempo com atividades que não gerassem lucro. Visto dessa forma, o fator tempo se tornou fundamental. A valorização do trabalho significou a racionalização do mundo e a eliminação do pensamento mágico como meio de salvação (WEBER, 1967).

O surgimento do VP ocorreu logo após o término da Primeira Guerra Mundial (1914-18). Depois, os soldados norte-americanos difundiram - VP nos países onde os EUA montaram suas bases militares, durante a Segunda Guerra Mundial (1939-45).

Um pouco antes do início da Primeira Guerra Mundial, os EUA já ocupavam o posto de maior economia industrial. Com a vitória no conflito houve um fortalecimento do setor transformando a nação em uma potência econômica (HOBSBAWM, 1995).

Nesse sentido, algumas conquistas sociais foram verificadas, tais como, o baixo número de desempregados, o aumento de salários e a redução da jornada de trabalho (HOBSBAWM, 1995). Estes fatores contribuíram para uma estabilidade emocional geral das famílias. Com isso, o poder de consumo da população aumentou.

Esse conjunto de características acabou atribuindo algumas funções sociais ao VP ou, em outras palavras, a classe alta norte-americana construiu através de disposições sociais adquiridas uma nova prática cultural com uma função específica (BOURDIEU, 1990).

Por enquanto, é importante saber que foi através desse prisma que o VP expandiu-se, primeiro dentro dos EUA e depois para outros países, como uma prática recreativa do Voleibol (SHEWMAN, 1995).

No caso do Brasil, não foi diferente, o VP surgiu no país respeitando o perfil amador $e$ distintivo (COUVILLON, 2002). Segundo as fontes históricas pesquisadas, a modalidade começou a ser praticada no final da década de 1930 como forma recreativa (CONFEDERAÇÃO BRASILEIRA DE VOLEIBOL, 2008) e como uma opção a mais para o Voleibol de Ginásio, este importado dos EUA, em 1916, através da Associação Cristã de Moços (BIZZOCCHI, 2004).

O VP desenvolveu-se primeiramente na cidade do Rio de Janeiro nas praias freqüentadas originalmente pelas elites (Copacabana, Ipanema e Leblon). Depois sua prática se difundiu ao longo da costa nacional e finalmente ganhando espaço no interior do país, longe das praias mas inserido nos clubes sociais de elite.

Em 1985, aproveitando a alta popularidade que o Voleibol brasileiro alcançara devido, principalmente, à profissionalização das equipes, o VP surgiu no cenário nacional como espetáculo esportivo de massa com a transmissão pela TV do I Hollywoody Vôlei de Praia. Essa foi a primeira evolução significativa deste esporte, que desencadeou transformações no panorama nacional e também mundial do VP. Este dado histórico justifica o início do recorte temporal, proposto no desenvolvimento desta pesquisa.

Em menos de 15 anos, o VP brasileiro tornouse referência internacional. Transformou-se de simples atividade de lazer em um produto espetacularizado. Foi a modalidade a ingressar mais rápido nos Jogos Olímpicos e o Brasil foi o maior impulsionador dessa conquista.

Em 1993, o então presidente do Comitê Olímpico Internacional (COI), o espanhol Juan Antonio Samaranch assistiu à etapa brasileira do circuito mundial e deu o seu aval para a entrada do VP no rol dos esportes olímpicos. Os Jogos Olímpicos de Atlanta - 1996, marcaram a estréia da modalidade na competição e, na sequência, os Jogos de Sydney - 2000 e Atenas - 2004 (limite do nosso recorte temporal) confirmaram a consolidação do VP como um produto espetacularizado. Diante desse cenário, sumariamente apresentado, levantamos a seguinte questão para análise: por que o desenvolvimento internacional do VP ocorreu no Brasil ao invés dos EUA? Para essa tarefa, foi necessário reavaliar o percurso histórico da modalidade.

\section{Surgimento do Voleibol de Praia}

O VP nasceu nas praias do sul da Califórnia, no início da década de 1920. Sinjin Smith e Neil Feineman acreditam na origem californiana do VP, segundo os autores: "Embora há cochichos não confirmados de ocasionais times de seis homens jogando nas praias do Havaí no início dos anos 20 , muitos relatórios localizam a origem 
do esporte em Santa Mônica, Califórnia." (SMITH; FEINEMAN, 1988, p. 2).

Esse desenvolvimento pode ser explicado devido a uma série de fatores interligados tais como, o término da Primeira Guerra Mundial, a força da economia norte-americana, as universidades, a Califórnia, o clima, a praia, o automóvel, o aumento no consumo e, finalmente, os clubes de praia.

Uma parte da análise trata do boom econômico, 1920-29 que ocorreu na sociedade norte-americana imediatamente após a Primeira Guerra Mundial. Como o conflito estava se desenrolando na Europa, entre países europeus, por conseguinte os mecanismos que operavam a guerra eram gerados pelos problemas e interesses dessas nações. Com isso, os EUA estavam distantes e se envolveram por um curto e decisivo período. Dessa forma, não houve estragos na sua economia, pelo contrário, a guerra fortaleceu-os grandemente.

Em 1913, os EUA já se haviam tornado a maior economia do mundo, produzindo mais de um terço de sua produção industrial [...]. É uma cifra espantosa. [...] após o fim da Primeira Guerra Mundial, os EUA eram em muitos aspectos uma economia tão internacionalmente dominante quanto voltou a tornar-se após a Segunda Guerra Mundial. Foi a Grande Depressão que interrompeu temporariamente essa ascensão. Além disso, a guerra não apenas reforçou sua posição como maior produtor industrial do mundo, como os transformou no maior credor do mundo. (HOBSBAWM, 1995, p. 101).

Essa foi uma condição invejável de supremacia e de estabilidade econômica que teve reflexos diretos dentro da sua sociedade. Seguindo esta linha de raciocínio, o fato mais importante é destacar que, com a vitória dos EUA e o fim da guerra, um expressivo número de militares praticantes de Voleibol desembarcou (muitos retornando, outros tantos se mudando) na ensolarada e promissora Califórnia portando consigo aquilo que o sociólogo francês Pierre Bourdieu classifica como capital simbólico, ou seja, detêm ou representam um papel de respeito na sociedade, são vistos como heróis nacionais, são exemplos a serem seguidos pela juventude, incorporam o nacionalismo e o amor à pátria. Muitos deles passaram a jogar VP nos clubes e reforçaram o habitus que é próprio aos integrantes circunscritos às mesmas disposições sociais (BOURDIEU, 1990).

Duas das mais famosas universidades da Califórnia, a University of California (UCLA) e a University of Southern California (USC) foram importantes para o desenvolvimento do VP, pois com a abertura do programa de Voleibol nessas universidades, muitos estudantes passaram a praticá-lo nas praias. A apropriação da modalidade pelos universitários confirma o caráter elitista do esporte, apesar de ser jogado em um local público, fora do campus universitário, tem nos seus integrantes os representantes de uma elite burguesa em ascensão e, portanto, detentora de um capital cultural, econômico e social agregados pela forte instituição escolar americana.

Outro elemento importante a ser discutido é o uso do automóvel como meio de transporte facilitador dos deslocamentos para as regiões beira-mar. Nessa análise, é preciso considerar os novos padrões de comportamento que surgiram na emergente sociedade norte-americana depois da breve recessão do período pós-guerra. Foi demonstrado, anteriormente, que uma visível transformação das estruturas sociais e econômicas estava em andamento nos EUA. Nesse sentido, houve melhoria no padrão de vida da população através da aquisição e uso de uma infinidade de bens materiais tais como, casa própria, luz elétrica, automóvel, eletrodomésticos, roupas, artigos esportivos e de lazer, acesso ao rádio e cinema, entre outros.

O uso do automóvel permitiu à população desfrutar a praia de maneira mais cômoda e com maior freqüência, o que aumentou as possibilidades de lazer nos balneários da Califórnia. Entre essas atividades recreativas estava o VP.

Bourdieu classifica como habitus de classe esse conjunto de elementos que fazem parte do modo de ser e que direcionam os comportamentos dos integrantes de um determinado grupo social (BOURDIEU, 2007). Se a posse do automóvel era importante, o uso que se fazia dele era ainda mais distintivo, ou seja, novos padrões de comportamento foram sendo adquiridos e valorizados de acordo com as representações sociais.

A participação dos clubes vem completar a análise, que começou tratando do contexto histórico do desenvolvimento dessa modalidade. Com a rápida proliferação dos clubes, mais conhecida como a "era dos clubes de praia", seus integrantes, muitos deles militares, passaram a se encontrar em um local privado que agregava uma elite de associados que compartilhavam interesses comuns como o esporte, por exemplo.

Os Beach Clubs desempenharam um papel fundamental no desenvolvimento do VP bem como as Universidades e as Forças Armadas: essas três instituições formaram os pilares da 
estrutura inicial da modalidade. Assim, o esporte expandiu seus horizontes, primeiro dentro dos EUA e depois para vários outros países dos cinco continentes. Seguindo essa lógica de desenvolvimento, discutiremos, a seguir, a expansão do VP.

\section{Amadorismo e divulgação}

Durante o verão de 1924, as competições de VP já eram as principais atividades esportivas dos clubes, os quais, eventualmente, jogavam uns contra os outros. Essas partidas interclubes foram os primeiros torneios de VP que se tem registro na Califórnia (COUVILLON, 2002).

As universidades reconheceram oficialmente a nova prática em 1950, e assim surgiu a primeira equipe: a UCLA Beach Volley National Team (FIORENTINO, 1996). A modalidade começava a organizar-se através de instituições que iriam futuramente gerenciar o esporte.

Durante o ano de 1965, os organizadores dos torneios norte-americanos se reuniram com 0 objetivo de planejar e coordenar um calendário de eventos, bem como definir o curso da modalidade; para isso, fundaram a California Beach Volleyball Association (CBVA). A instituição ficou então responsável por promover o esporte através de um sério planejamento, organização e condução dos torneios da maneira mais efetiva e profissional possível (COUVILLON, 2002).

Em 1972, apareceu o primeiro patrocinador, um pequeno restaurante da praia de Santa Monica, chamado Nick Fishmarket o qual premiou os jogadores com US $\$ 1,5$ mil. Em 1974, o primeiro torneio de duplas masculinas comercialmente patrocinado ocorreu em San Diego, na presença de 250 espectadores. Dois anos mais tarde, a Volleyball Magazine e a Olympia Beer patrocinaram o primeiro Olympia World Championship of Beach Volleyball, em State Beach, com um prêmio de US\$ 5 mil e a presença de mais de 30 mil espectadores (SMITH; FEINEMAN, 1988). O conceito de evento começava a tomar vida.

Dessa forma, ainda em 1976, David Wilk e Craig Masuoka (empregados da Volleyball Magazine) percebendo o ilimitado potencial comercial do VP, abandonaram a revista e montaram a Events Concepts, uma companhia de promoção de eventos, criada com o objetivo de expandir o circuito. Em 1983, o esporte cresceu enormemente atingindo proporções nacionais com doze torneios em quatro estados. Quem decidiu apostar na modalidade, dessa vez, foi a Miller Brewing Company, proprietária da cerveja
Lite Beer, que distribuiu US\$ 137 mil em prêmios (SMITH; FEINEMAN, 1988).

Ainda no mesmo ano, a mídia impulsionou o esporte em duas frentes: a revista Sports Illustrated e o jornal USA Today passaram a dedicar espaços permanentes ao VP. As reportagens eram simpáticas e chamativas. A outra exposição veio através da série de televisão Magnum, protagonizada pelo ator Tom Selleck, um jogador e entusiasta da modalidade.

Selleck decidiu incluir, permanentemente, o estilo de vida alegre do VP em seu seriado, para isso, precisava de profissionais que dominassem as técnicas da modalidade, além de atuarem como atores. Recrutou então os irmãos Andrew e Sinjin Smith (que além de jogadores, também trabalhavam como modelos) para o episódio que iria mostrar o VP ao país inteiro e em vários países do mundo, incluindo o Brasil (SMITH; FEINEMAN, 1988). Após o lançamento do programa, Smith percebeu a força da TV e passou a enxergar novas possibilidades para 0 esporte.

Ainda em 1983, a Events Concepts detinha os direitos administrativos do circuito norteamericano de VP, buscando mais dinheiro para os torneios, tentando agradar os patrocinadores e procurando expandir as relações com a ESPN TV, já interessada em cobrir os eventos. Alguns desentendimentos começaram a aflorar: o sistema de pontos e a nova bola tornaram-se assuntos divergentes entre a empresa e os jogadores.

Descontentes com a Administração da Events Concepts, os jogadores começaram a organizar reuniões para discutir seu futuro no esporte. Esses encontros deram origem a uma das mais importantes instituições do VP mundial, uma vez que mudaria, definitivamente, os rumos da modalidade.

Essa instituição foi idealizada como uma forma de associação entre os jogadores de VP com o intuito de atingir a total profissionalização, bem como assumir o controle da atividade. Assim, em 21 de julho de 1983, nasceu a Association of Volleyball Professional (AVP), entidade fundada pelos próprios jogadores com os seguintes objetivos específicos: a) aumentar a premiação em dinheiro; b) oferecer mais oportunidades para os patrocinadores individuais; c) distribuição da premiação em dinheiro de acordo com os padrões da AVP (até o nono lugar); d) aprovação de todo equipamento usado em todos os eventos; e) aprovação do sistema de pontos e das regras do jogo; f) contínua influência na organização e 
direção do Pro Beach Volleyball Series (SMITH; FEINEMAN, 1988).

Pelos objetivos da associação, ficou mais do que óbvio que a sua criação teve como meta proteger os interesses dos jogadores e preservar a integridade do VP, ao passo que, no centro de tudo estava o aumento do sucesso comercial do esporte. Em outras palavras, a luta pelo controle do campo estava declarada, como evidenciamos, a seguir.

Por meio da AVP, tanto os eventos como a imagem dos jogadores que a integravam passaram a ser comercializados de forma organizada. Os conceitos de marketing e promoção se tornaram familiares dentro do dia-adia do VP. O volume de dinheiro, profissionalismo, desenvolvimento e expansão que a modalidade experimentou com o gerenciamento da AVP foi algo que chamou a atenção da Federação Internacional de Voleibol (FIVB).

Em 26 de julho de 1984, por ocasião do Congresso Técnico de Long Beach, em Los Angeles, tomou posse o novo presidente da FIVB, o mexicano Rubén Acosta. O principal objetivo de Acosta foi otimizar o desenvolvimento do Voleibol. Para isso, um extenso planejamento foi adotado e uma nova estruturação foi estabelecida (BAACKE, 1989). Na ocasião da posse do novo presidente, a FIVB contava com 156 países filiados. E qual era a dimensão da AVP?

A AVP possuía uma forte representatividade no cenário esportivo norte-americano. Era uma associação totalmente independente, ou seja, não estava subordinada a nenhuma outra entidade administrativa. A associação funcionava como uma empresa capitalista gerenciada pelos próprios jogadores. Enquanto a AVP já contava com uma sólida organização nos seus eventos, a FIVB ainda estava dando seus primeiros passos na elaboração de um plano de metas para 0 desenvolvimento mundial do VP.

Desde a sua criação, a FIVB passou a comandar o Voleibol na esfera internacional. Cada país filiado possui sua federação nacional e conta com soberania dentro de seu território. Como uma entidade legal, cada federação tem autoridade de firmar contratos, realizar eventos e adquirir direitos dentro dos limites definidos pela legislação nacional, respeitando e reconhecendo o estatuto e suas obrigações para com a entidade maior, a FIVB. A estrutura administrativa da FIVB é composta de órgãos que são descritos e estabelecidos pelo estatuto da instituição. Nessa estrutura, as decisões são subordinadas aos chamados Board of Administration and Executive Committee (ACOSTA, 1989).
A AVP se tornou uma das mais fortes e representativas associações esportivas do mundo. Dessa forma, a briga de interesses entre AVP e FIVB estava começando. Este assunto será retomado, mais adiante, quando o texto apresentar o campo do VP, no Brasil, que se beneficiou dessa disputa.

Em 1986, o torneio profissional de duplas da AVP recebeu cobertura da TV à cabo via Prime Ticket. As transmissões tiveram o crédito do canal ABC. A modalidade expandiu sua popularidade $e$ seus interesses, com isso, outra instituição foi formada: a Women's Professional Volleyball Association (WPVA), uma versão feminina da AVP que veio fortalecer ainda mais os interesses dos jogadores (COUVILLON, 2003).

Com toda essa exposição midiática, a fabricante de tequila Jose Cuervo patrocinou três torneios durante o ano de 1988 e o prêmio para cada um deles era a quantia recorde de US $\$ 100$ mil, em dinheiro. Atenta ao retorno publicitário do espetáculo do VP, a Miller Lite Beer concordou em patrocinar mais de vinte torneios e assinou com a AVP um contrato por três anos, no valor de US\$ 4,5 milhões (VOLLEYBALL WORLD WIDE, 2003).

Com o aumento nas transações comerciais, podemos notar uma intrincada rede de interesses e disputas entre os agentes que compõem o campo esportivo do VP profissional norteamericano. Essa busca pelo poder, ilustrada pelas lutas no interior do campo, é que opera o funcionamento do campo (BOURDIEU, 1983).

A partir do momento que a modalidade passou a ter a possibilidade de movimentar grandes quantias em dinheiro, rapidamente surgiram instituições/entidades a fim de se apoderar de um monopólio específico. Bourdieu defende que as estruturas de um campo convivem em constantes disputas entre dominados e dominantes, sobre esse ponto, o autor é enfático: "[...] sabe-se que em cada campo se encontrará uma luta, da qual se deve, cada vez, procurar as formas específicas, entre o novo que está entrando e que tenta forçar o direito de entrada e o dominante que tenta defender 0 monopólio e excluir a concorrência" (BOURDIEU, 1983, p. 89).

Com a criação da AVP, os órgãos que dirigiam o esporte até então, a United States Volleyball (USAVB), com poder nacional e a FIVB, com poder mundial - começaram a pressionar a associação para que esta se submetesse ao controle da entidade norte-americana (hierarquicamente subjugada a Federação Internacional), proposta que os jogadores rejeitaram prontamente. 
Assim sendo, a AVP foi a grande impulsionadora desse esporte no mundo até 0 Brasil entrar, definitivamente, no negócio. A partir da inserção e apropriação da modalidade, pelo Brasil, o caráter de espetáculo ganharia outro significado. Sobre a trajetória brasileira nesse processo, buscamos explicitar a formação do campo nacional do VP. Com essa perspectiva em foco, iniciamos a próxima parte.

\section{Voleibol de Praia no Brasil}

Fiel as particularidades específicas do seu campo de nascimento, o VP desenvolveu-se no Brasil seguindo o modelo americano de prática de lazer restrito às elites, principalmente na orla marítima carioca, berço e principal centro da modalidade no país.

Na década de 1950, a modalidade já estava sendo bastante praticada pela elite social nas praias de Ipanema, Copacabana e Leblon, localizadas na cidade do Rio de Janeiro. Foi por meio dessa elite que a modalidade surgiu no Brasil como uma "novidade" que acabou funcionando como elemento distintivo pois espelhava a posse de um capital cultural diferenciado (BOURDIEU, 2007).

Dentro de um campo em formação, Bourdieu destaca a idéia do habitus como um elemento importante, possuindo uma enorme potência geradora, como se fosse uma máquina transformadora que faz com que nós reproduzamos as condições sociais de nossa própria produção de maneira imprevisível (BOURDIEU, 1983).

Do conhecimento da estrutura da FIVB, da USAVB e da AVP, descritos anteriormente, passamos agora a discutir a estrutura da entidade que dirige o VP no Brasil, a Confederação Brasileira de Voleibol (CBV). Esta é uma instituição federal de administração esportiva, fundada na cidade do Rio de Janeiro, em 09 de agosto de 1954, é filiada ao Comitê Olímpico Brasileiro (COB) e a FIVB. Um fato importante foi a entrada de Carlos Arthur Nuzman na presidência da entidade. Nuzman foi eleito em 18 de janeiro de 1975, sustentado por seis reeleições, ficou no cargo até 07 de janeiro de 1997 (CONFEDERAÇÃO BRASILEIRA DE VOLEIBOL, 2007).

Quanto às questões burocráticas, a CBV detém os direitos sobre os eventos previstos no calendário de VP da entidade. A estrutura administrativa da CBV conta, atualmente, com 27 federações estaduais filiadas, agência de marketing, um departamento específico para cuidar dos assuntos referentes ao VP chamado de Unidade de Competições de Praia (UCP). Além disso, conta com a Unidade de Competições Nacionais (UCN), a Unidade das Seleções (USE), a Unidade de Eventos (UE) e a Unidade Viva Vôlei (UVV) (KASZNAR; GRAÇA FILHO, 2006).

Este modelo de gerenciamento esportivo usado pela CBV, na qual cada uma das suas unidades funciona como uma empresa, ou seja, opera com orçamento próprio e é administrada por um diretor ou gerente, é equivalente à configuração de uma holding company.

Após a descrição da parte diretiva do VP brasileiro, retornaremos ao ano de 1985 para que possamos compreender como foi, continuamente, se formando esse campo. Aproveitando o momento de grande popularidade que os ídolos do Voleibol brasileiro desfrutavam logo após os Jogos Olímpicos de Los Angeles - 1984, a Koch Tavares, uma empresa com sede na cidade de São Paulo, com know-how e pioneira em marketing esportivo na América do Sul, teve a iniciativa de promover o I Hollywood Vôlei de Praia.

Nesse sentido, o VP "pegou uma carona" no já institucionalizado Voleibol de Ginásio e, dessa forma, foi transmitido ao vivo pela TV Globo em rede nacional como um espetáculo esportivo.

É produtivo acompanhar o relato do diretor de marketing da Koch Tavares, empresa responsável pelo desenvolvimento do VP, tanto no Brasil quanto no exterior: "O Brasil tem uma extensa faixa litorânea, com praias lindíssimas. $O$ vôlei de quadra nacional estava em plena ascensão com a conquista da medalha de prata na Olimpíada de Los Angeles, em 1984. Era o momento ideal para juntar as duas coisas e apostar no vôlei de praia." (VON OERTZEN, 1996, p. 9).

A imprensa local publicou uma nota destacando o nome dos jogadores como chamariz e informando que o torneio, com "regras próprias", seria disputado em duplas (EXIBICÕES, 1985, p. 22). O termo foi usado para justificar a novidade desse tipo de competição, já que no Brasil o VP ainda não possuía um conjunto de regras padronizadas, nem por parte da CBV, nem tão pouco pela FIVB. Nessa época, somente a AVP possuía uma estrutura regimentar para a modalidade.

A boa aceitação do torneio incentivou os promotores a ampliar $\mathrm{o}$ evento, que funcionou como impulso ao crescimento do VP no Brasil. Em 1986, a CBV juntou-se à Koch Tavares na organização e decidiram promover $\mathrm{O}$ VP em 
âmbito mundial. Para isso, organizaram, no Brasil, um torneio com a presença dos jogadores americanos, o Hollywood Vôlei de Praia Internacional, também chamado de II Hollywood Vôlei.

A identificação do VP com a cidade do Rio de Janeiro impressionou os jogadores norteamericanos. Ao final, o então presidente da CBV, Carlos Arthur Nuzman agendou uma reunião com o então presidente da FIVB, Rubén Acosta para entregar-lhe os vídeotapes de todos os jogos do II Hollywood Vôlei de Praia. Por meio dessa estratégia, Nuzman pretendia promover o VP brasileiro e mundial e, para isso, além de sua "habilidade" e força política, ele contava ainda com a excelente organização do evento. Sobre seus planos: "o nosso objetivo era demonstrar o alto grau de organização e desenvolvimento do vôlei de praia brasileiro, e criar no Rio de Janeiro o Mundial da modalidade, que seria disputado em 1987, entre os principais países praticantes desse esporte." (NUZMAN, 1996, p. 11).

O campo do VP brasileiro estava começando a estruturar-se dentro de uma perspectiva de oferta e demanda. Dentro desse contexto, identificamos o monopólio das instituições FIVB, CBV e Koch Tavares que desde 0 início dominam este mercado.

Para que possamos compreender 0 desenvolvimento da modalidade no Brasil, é preciso pensar nas transformações, ou ainda, metamorfoses que vêm ocorrendo dentro do campo esportivo, a fim de entender como o VP brasileiro avançou e conquistou prestígio.

\section{Evolução e reconhecimento}

Através do empenho da CBV junto à FIVB, os planos traçados por Carlos Arthur Nuzman, para o desenvolvimento do VP no Brasil começaram a se concretizar. Com esse objetivo, o Congresso de Praga da FIVB, realizado nos dias 5 e 6 de setembro de 1986, aprovou e oficializou o I Campeonato Mundial de Voleibol de Praia, tendo como cenário o posto 10 , na praia de Ipanema, no Rio de Janeiro, a ser realizado no ano seguinte, ou seja, 1987.

O maior desafio que os organizadores brasileiros enfrentaram foi com relação ao regulamento da competição, já que, como dito anteriormente, esse esporte não tinha um corpo de regras padronizadas internacionalmente. Mais uma vez, usando a sua capacidade administrativa, Carlos Arthur Nuzman não só reconheceu, como transferiu um potencial de poder à Koch Tavares, para que esta empresa elaborasse toda a parte organizacional, normativa, regulamentar e regimental do I Campeonato Mundial de Voleibol de Praia.

Contando com essa abertura e baseada principalmente na estrutura e na experiência da AVP, a Koch Tavares formulou um documento detalhado e completo sobre os aspectos técnicos que estariam envolvidos numa competição desse porte, desde as regras do jogo em si, sistema de disputa, chaves, torneio classificatório, torneio principal, normas para utilização dos espaços de publicidade, entre outras particularidades. Por outro lado, a CBV organizou toda a parte comercial do evento junto aos promotores, patrocinadores, apoiadores, produtores de televisão e demais agentes do campo. A padronização e oficialização das regras contribuíram para a estruturação da modalidade em termos internacionais.

As regras elaboradas para o I Campeonato Mundial de praia foram aprovadas pela Federação Internacional e passarão a ser obrigadas em todo o mundo, num processo de uniformização do regulamento e normas. Para obter a padronização, a Federação Internacional distribuirá um manual básico para todos os seus filiados. (NUNES, 1987, p. 44).

Com a importante chancela da FIVB, o Brasil abriu caminho para 0 desenvolvimento internacional da modalidade, e o VP brasileiro passou a ser referência mundial em termos estruturais e políticos.

Uma arena com 8 mil lugares recebeu um público de aproximadamente 100 mil pessoas durante o evento, que distribuiu uma premiação de US\$50 mil em dinheiro. Na cerimônia de encerramento, Mike O'Hara, diretor de projetos da FIVB e vice-presidente do Comitê Organizador dos Jogos Olímpicos de Los Angeles, destacou a importância da praia de Ipanema dentro do cenário internacional da modalidade: "Ipanema representa para 0 voleibol de praia 0 que Wimbledon representa para o tênis." (O'HARA, 1988, introdução).

Com o sucesso do I Campeonato Mundial de Voleibol de Praia e o aval da FIVB, o Brasil começaria então a conquistar a cena internacional, passando não só a produzir como também vender o espetáculo, tornando-se o principal centro da modalidade no mundo.

\section{Mercantilização e espetacularização do Voleibol de Praia}

Comprovando o mérito brasileiro com a realização do I Mundial, a CBV e a Koch Tavares promoveram em fevereiro de 1988 o II Mundial de Voleibol de Praia, consolidando de vez a 
modalidade no calendário esportivo nacional e internacional.

Após a realização do II Mundial, a modalidade experimentou um crescimento em muitos países. Rubén Acosta, o então presidente da FIVB, esteve presente no Rio de Janeiro a fim de assistir às partidas semifinais e finais do torneio $e$ anunciou três decisões que impulsionaram 0 desenvolvimento internacional da modalidade. A primeira foi a criação de um Conselho Mundial de Voleibol de Praia, sob a presidência do brasileiro Carlos Arthur Nuzman; a segunda tornou a Koch Tavares a agência de marketing da FIVB para assuntos relacionados ao VP; e a terceira estabeleceu que a partir de 1989 o mundial fosse disputado em forma de circuito, com etapas em vários países (FEDERAÇÃO INTERNACIONAL DE VOLEIBOL, 1996).

Com o reconhecimento e aval da FIVB, Carlos Arthur Nuzman (CBV) e a Koch Tavares conquistaram potencial de poder em escala global e, dessa forma, o Brasil começou então a dominar o campo internacional do VP, produzindo e vendendo o espetáculo. Com esse acúmulo de capital específico. Nuzman tornou-se politicamente mais forte e a Koch Tavares exportou seu know-how, desenvolvendo projetos de torneios similares ao do Brasil em outros países. Foi dentro dessa confluência de interesses que surgiu $O$ Circuito Mundial Masculino de Voleibol de Praia, o FIVB World Series Championship, em 1989. O Campeonato Mundial foi mantido e passou a figurar como a etapa principal do circuito.

As primeiras etapas do Circuito Mundial, organizadas pela FIVB, se converteram em um grande sucesso comercial com milhares de espectadores ocupando as arenas. Os prêmios em dinheiro chegaram a US $\$ 50$ mil em cada torneio (FIORENTINO, 1996).

Um divisor de águas na trajetória do VP brasileiro aconteceu em 1991. Com iniciativa da CBV e patrocínio do Banco do Brasil foi criado o circuito brasileiro, que recebeu o nome de Banco do Brasil Open de Vôlei de Praia. Inicialmente, o torneio contava apenas com duplas masculinas, em cinco etapas que percorreram diferentes capitais do Nordeste.

Em 1992, houve um rápido crescimento e o circuito passou a ter 16 etapas no masculino e, finalmente, a estréia do circuito feminino, com cinco etapas. Durante os meses de agosto a dezembro, o espetáculo do VP percorreu mais de quatro mil quilômetros, passando por 16 cidades brasileiras. Pela primeira vez algumas etapas foram realizadas em cidades que não possuíam praia. Desta forma, o VP foi migrando para o interior do Brasil e conquistando novos mercados. As etapas foram então sediadas em praças, parques ou mesmo em estacionamentos de shoppings. Mais de quinhentos atletas participaram da temporada de 1992, disputando uma premiação que somou mais de US $\$ 300 \mathrm{mil}$ (BANCO DO BRASIL OPEN, 1993).

Voltando ao Circuito Mundial, o biênio 1992-93 foi marcante para o VP brasileiro e mundial, na medida em que teve uma atuação marcante dos agentes e instituições que estavam começando a controlar o campo. Os números das relações mercantis e de espetáculo quebraram todos os recordes anteriores. A temporada 1992-93, que começou na Espanha e terminou no Brasil, contou com 45 países participantes, mais de 50 milhões de telespectadores e 33 horas de transmissão ao vivo (늘RIA, 1993).

O ano de 1993 foi importante na história do VP mundial. No mês de fevereiro, uma estratégia política da FIVB, CBV e Koch Tavares foi decisiva para transformar a modalidade em esporte olímpico. Em outras palavras, a CBV montou um megaevento em Copacabana e Nuzman convidou Juan Antonio Samaranch, presidente do Comitê Olímpico Internacional (COI) e John Payne, presidente do Comitê Organizador dos Jogos Olímpicos de Atlanta - 1996 (ACOG) - os quais se mostram "assombrados" pelo espetáculo, pela cobertura da TV, da imprensa e particularmente pelos 140 mil espectadores que compareceram à arena em apenas uma semana. Poucos meses depois, em Monte Carlo e, contrariando algumas disposições do COI, Juan Antonio Samaranch decidiu reconhecer o VP como esporte olímpico (FIORENTINO, 1996).

Este evento retratou perfeitamente qual era a dimensão do VP no cenário esportivo mundial: um rápido crescimento em um curto período de tempo, apresentando um desenvolvimento em termos administrativo, políticos, técnicos, organizacionais, e promocionais. Dentro dessa perspectiva, o VP estava tornando-se um negócio poderoso e lucrativo.

Às vésperas da maior vitrine promocional para o VP - os Jogos de Atlanta - a FIVB investiu, através da Koch Tavares - sua agência de marketing - e emplacou, definitivamente, o World Series como seu principal produto:

Em 1995 o Vôlei de Praia experimentou um boom em todo o mundo. A FIVB se expandiu aos 5 continentes com a participação de representantes de 29 países e uma premiação total de US\$ 3.650 .000 e mais de 800.000 espectadores ao vivo e 50 milhões de telespectadores. O conflito entre a FIVB, AVP e 
WPVA está longe de chegar a uma solução. (FIORENTINO, 1996, p. 9).

Por sua vez, o campo esportivo do VP norteamericano continuava sobre o domínio dos jogadores e jogadoras, através da AVP e WPVA. É fácil notar a força dessas duas associações, basta conferir a dimensão das negociações.

Em 1991, a AVP organizou o primeiro King of the Beach Tournament (Torneio Rei da Praia) que foi acrescentado ao seu calendário de eventos. Em 1993, o canal NBC transmitiu ao vivo dez eventos da AVP, com uma audiência estimada em 600 mil telespectadores e uma premiação total de US\$ 3,7 milhões em dinheiro. Em 1994, foram 27 eventos que percorreram as principais cidades do seu extenso território. Destes, a NBC transmitiu dez (21 horas). A Evian patrocinou uma etapa que foi realizada dentro de um do mais prestigiados ginásios do mundo, o Madison Square Garden, em Nova lorque, numa estratégia promocional inédita que teve repercussão internacional. A premiação total da temporada chegou a US\$ 4 milhões em dinheiro. Em 1995, o total de eventos da AVP chegou a 29 e a Evian resolveu expandir para quatro o número de torneios de Beach Volleyball indoor (Washington, Boston, Minneapolis e Nova lorque), criando um novo circuito que foi batizado de Evian Indoor Tour (VOLLEYBALL WORLD WIDE, 2003).

Por outro lado, no Brasil, o campo esportivo do VP se mostrava em pleno desenvolvimento, ou melhor, já era possível falar na existência de um campo brasileiro para o VP. O domínio desse espaço estava nas mãos das instituições dirigentes, ou seja, FIVB, CBV, Koch Tavares bem como do principal patrocinador do circuito nacional - o Banco do Brasil. O Circuito Banco do Brasil percorreu, em 1995, 17 cidades, de Norte a Sul do país.

Apesar de ainda não possuir a dimensão profissional e comercial do campo norteamericano, o VP brasileiro era politicamente forte em termos internacionais, ou seja, os dirigentes brasileiros faziam parte do FIVB Governing Body da modalidade.

Em outros países a estrutura da modalidade se mostrava de seguinte forma: na Austrália já havia um circuito profissional de VP (HISTORY OF BEACH VOLLEYBALL, 2011). Na Europa, os jogadores se organizaram em uma associação, seguindo o exemplo da AVP. Assim nasceu a Giocatory Associati di Pallavollo de Spiagia (Associação de Jogadores de Voleibol de Praia). $\mathrm{Na}$ Espanha, uma espécie de associação chamada Club Voleibol San Jose filiou os jogadores, que participaram de vários circuitos durante o verão. O mais importante era o Circuito Ballantines, que pagava ótimos prêmios e percorria as melhores praias do país. Na Suíça, aconteceu o primeiro campeonato internacional, em Lausane (GOOD NEWS, 1993). No México, existia o maior torneio amador de VP do mundo, sediado em Estero Beach (SHEWMAN, 1995). Demais países como Argentina, Chile, Canadá, Cuba, Portugal, Alemanha, Áustria, França, Noruega, Itália, Japão, Rússia e Nova Zelândia contavam com seus circuitos nacionais amadores ou torneios isolados durante o verão.

Em síntese, pela realidade do VP internacional, apresentada em meados da década de 1990, podemos perceber a supremacia estrutural dos dois principais centros da modalidade no mundo, o Brasil e os EUA. E no centro de toda essa constituição estava a disputa pela hegemonia do campo entre as duas instituições concorrentes, a FIVB e a AVP. Foi dentro desse contexto que o VP marcou a sua estréia nos Jogos Olímpicos de Atlanta - 1996.

Entretanto, levantamos duas questões fundamentais. Por que o Brasil tornou-se o promotor internacional do VP? Não caberia aos EUA essa função, já que são os inventores do Voleibol e reinventores do VP, com larga tradição, experiência, estrutura e know-how, em um campo consolidado com associação profissional, circuito profissional, público, patrocinadores, televisão, enfim, um campo com o rentável movimento da oferta e demanda?

Essas questões dizem respeito ao mesmo assunto e podem ser respondidas, em linhas gerais, pela luta pelo poder entre a FIVB e a AVP, disputa essa que vem moldando o campo desde que 0 VP foi transformado em business, característica que engloba a mercantilização e a espetacularização dos seus eventos e que teve expansão internacional através da promoção das instituições e agentes brasileiros.

Com a estréia nos Jogos Olímpicos, a modalidade alcançou prestígio e ampliou seu potencial mercadológico. Após 0 bom desempenho comercial obtido também nos Jogos Olímpicos de Sydney - 2000, a FIVB percebeu que poderia aumentar ainda mais o mercado internacional do VP e, segundo essa lógica, organizou uma seqüência de campeonatos mundiais referentes às categorias de base. Aproximando essa estratégia ao pensamento de Bourdieu, constatamos que a FIVB considerou "[...] o conjunto de práticas e de consumos esportivos oferecidos aos agentes sociais [...] como uma oferta destinada a encontrar uma 
certa demanda social." (BOURDIEU, 1983, p. 136, grifo do autor).

Desse modo, a FIVB percebeu que, naquele momento, tinha nas mãos um excelente produto e lançou-o no universo das práticas e dos consumos esportivos disponíveis e socialmente aceitáveis (BOURDIEU, 1983). Para Bourdieu, esta é uma estratégia de evolução da produção. Nesse sentido, o VP é um espetáculo produzido por profissionais e destinado ao consumo de massa.

[...] o desenvolvimento, no interior desse campo, de uma indústria do espetáculo esportivo que, submetida às leis da rentabilidade, visa a maximizar a eficácia minimizando os riscos (o que, particularmente, acarreta a necessidade de um pessoal técnico especializado e de uma verdadeira gerência científica, capaz de organizar racionalmente o treinamento e a manutenção do capital físico dos profissionais - pensemos por exemplo no futebol americano, onde o corpo de treinadores, médicos, public relations, excede o corpo de jogadores e serve, quase sempre, de apoio publicitário a uma indústria de equipamentos e de acessórios esportivos) (BOURDIEU, 1983, p. 145-146, grifo do autor).

Nesta perspectiva, no ano de 2003 foi iniciada uma parceria entre a FIVB e a Swatch Company, uma empresa suíça de relógios. Seguindo as tendências do marketing esportivo, o nome do patrocinador passou a fazer parte do nome do evento. Dessa forma, a Swatch deu o nome ao Circuito Mundial de Voleibol de Praia Profissional da FIVB que passou a ser oficialmente chamado de Swatch FIVB Beach Volleyball World Tour. Além do título, foi criada uma nova logomarca para o circuito e também introduzida a tecnologia da Swatch, por meio de placares eletrônicos e instrumentos para medir a velocidade da bola durante as partidas (FEDERAÇÃO INTERNACIONAL DE VOLEIBOL, 2011).

O espetáculo da modalidade atingiu seu ápice com a realização dos torneios mais profissionais vistos até então. O Brasil organizou em Copacabana, Rio de Janeiro, no mês de outubro de 2003, os Campeonatos Mundiais de Voleibol de Praia Masculino e Feminino. Vale lembrar que o campeonato mundial é o evento mais importante e especial do FIVB World Series. As transmissões feitas pela Rede Globo atingiram uma audiência de 17 pontos para as partidas femininas e de 12 pontos para os jogos masculinos. A distribuição televisiva alcançou mais de 200 países (FEDERACCÃO INTERNACIONAL DE VOLEIBOL, 2011).

A FIVB entrou com seus patrocinadores Swatch, Mikasa e Speedo. A CBV entrou com Banco do Brasil, Prefeitura do Rio de Janeiro,
Siemens, Fisk, Campari e Coca-Cola. A premiação chegou a US $\$ 800$ mil em dinheiro (SHOW NA PRAIA, 2003).

A temporada 2004 contou com a realização do torneio de VP dos Jogos Olímpicos e com mais 26 eventos mundiais referentes ao circuito, o qual distribuiu uma premiação de quase US\$ 5,5 milhões em dinheiro (FEDERAÇÃO INTERNACIONAL DE VOLEIBOL, 2011).

O ponto alto da temporada foi o torneio de VP dos Jogos Olímpicos de Atenas, o qual confirmou a popularidade e o prestígio comercial da modalidade. Pela primeira vez em uma edição dos Jogos Olímpicos, um programa de entretenimento foi implantado com o envolvimento de 12 dançarinas, disc-jóqueis, apresentadores poliglotas e diretores de produção (FEDERAÇÃO INTERNACIONAL DE VOLEIBOL, 2011).

Diante das constatações levantadas até aqui, entendemos que o voleibol de praia vem sendo direcionado para a espetacularização como um produto comercial de alcance global.

\section{Considerações Finais}

No Brasil, o campo esportivo do VP está intimamente atrelado às estruturas políticoadministrativas das instituições que regem a modalidade. Dessa forma, entidades como FIVB, CBV, Koch Tavares, Banco do Brasil e Rede Globo controlam a modalidade.

Nos EUA, o campo esportivo do VP apresentase como um espaço social independente. Quem detém plenos poderes sobre a modalidade são os próprios jogadores, organizados em associações representativas, as famosas AVP e WPVA. Estas associações funcionam como empresas, capitalizando todos os lucros que o VP tem capacidade de gerar como produto mercantilizado e espetacularizado.

Bourdieu classifica as relações que moldam um campo como relações de forças objetivas, ou melhor, para cada movimento que determinado agente efetua no interior do campo sempre existe uma intenção de obter lucro. Este lucro vem em forma de acúmulo de capital e só se define como tal num determinado mercado (BOURDIEU, 1983). Dessa forma, encontramos no material histórico pesquisado alguns acontecimentos que justificaram as estratégias que moldaram 0 campo em questão. A posse de Rubén Acosta no comando da FIVB, em 1984, trouxe dinamismo e arrojo à entidade. Com essa política e aproveitando o momento de crescimento do VP, Acosta visualizou um extraordinário meio de promoção pessoal: 0 dirigente percebeu que 0 campo do VP, nos EUA, era um espaço 
realmente impenetrável para a FIVB, pois, como foi descrito, anteriormente, a AVP não aceitava ser controlada pela USAVB. Além disso, havia o prestígio político de Carlos Arthur Nuzman e seu empenho junto a FIVB em relação ao VP, a capacidade organizacional da Koch Tavares, o profissionalismo da CBV e o entusiasmo do público brasileiro para com a modalidade. Diante desse contexto, o então presidente da FIVB resolveu reconhecer, investir e credenciar o Brasil como o promotor internacional do VP.

Todas as lutas travadas no interior do campo têm por objetivo o acúmulo de capital pelos que disputam a hegemonia do campo (BOURDIEU, 1983). Nesse caso, ficou aparente a força política da FIVB - não podendo contar com parte dos lucros do mercado do VP norte-americano, a instituição maior do voleibol mundial passou a ver a AVP como uma liga "pirata". A briga entre AVP e FIVB ainda está longe de ter um fim, embora as negociações "oficiais" visando a "unificação" começaram em 1988.

Até o presente momento, a FIVB vem vencendo a "queda de braço" com a AVP, assumindo, dessa forma, o controle da modalidade. O Brasil tem desempenhado papel fundamental dentro desse contexto e tirado vantagem dessa disputa, passando ele próprio a ser a referência mundial desse esporte.

De posse dessas análises, buscamos minimamente elucidar a questão problematizadora inicial deste estudo, isto é, o porquê do Brasil ser a atual referência internacional no VP e não os EUA. Não obstante, destacamos o valor e a possibilidade de leituras sociológicas do esporte a partir de conceitos, noções e modelos consistentes como o de Pierre Bourdieu.

Para finalizar, não pretendemos com estas constatações realizar previsões. Entretanto, diante das conclusões desta pesquisa e das novas configurações que se apresentam, abremse novas perspectivas de estudos dentro do campo esportivo internacional do VP.

\section{Referências}

ACOSTA, R. The FIVB structure operation and spirit of its global programme. In: FEDERATION INTERNATIONALE DE VOLEYBALL (FIVB). FIVB Coaches Manual. Lausane: FIVB, 1989.

AFONSO, G. F. Voleibol de praia: uma análise sociológica da história da modalidade (1985 2003). 2004. 222 f. Dissertação (Mestrado em Educação Física) - Setor de Ciências Biológicas, Universidade Federal do Paraná, Curitiba, 2004.
BAACKE, $H$. Development and status of volleyball. In: FEDERATION INTERNATIONALE DE VOLEYBALL (FIVB). FIVB Coaches Manual. Lausane: FIVB, 1989.

BANCO DO BRASIL OPEN. Informativo da CBV. Rio de Janeiro: CBV, 1993.

BIZZOCHI, C. O voleibol de alto nível: da iniciação à competição. Barueri: Manole, 2004.

BOURDIEU, P. Questões de sociologia. Rio de Janeiro: Marco Zero, 1983.

BOURDIEU, P. Coisas ditas. São Paulo: Brasiliense, 1990.

BOURDIEU, P. A distinção: crítica social do julgamento. São Paulo: Edusp, 2007.

CONFEDERAÇÃO BRASILEIRA DE VOLEIBOL. Show na Praia. Vôlei - Informativo da CBV, Rio de Janeiro, ano 1, n. 9, nov. 2003.

CONFEDERAÇÃO BRASILEIRA DE VOLEIBOL. Institucional: história. Disponível em: $<$ http://www.cbv.com.br/v1/institucional/quem so mos.asp >. Acesso em: 12 jul. 2007.

CONFEDERAÇÃO BRASILEIRA DE VOLEIBOL. Institucional: história do voleibol de praia.

Disponível

em:<http://www.cbv.com.br/cbv2008/institucional/ histpraia.asp >. Acesso em: 10 dez. 2008.

COUVILLON, A. Sands of time: the history of beach volleyball. United States of America: Information Guides, 2002. v. 1.

COUVILLON, A. Sands of time: the history of beach volleyball. United States of America: Information Guides, 2003. v. 2.

EXIBIÇÕES em Guarujá e Santos. O Estado de S. Paulo, São Paulo, 02 fev. 1985. Caderno Esportes, p. 22.

FEDERAÇÃO INTERNACIONAL DE VOLEIBOL (FIVB). Beach volleyball history. Disponível em: $<$ http://www.fivb.org/EN/BeachVolleyball/History.a sp >. Acesso em: 18 fev. 2011.

FEDERAÇÃO INTERNACIONAL DE VOLEIBOL. The game: biography of beach volleyball. Disponível 
em:<http://www.fivb.ch/TheGame/story.htm>.

Acesso em: 18 fev. 2011.

FEDERATION INTERNATIONALE DE

VOLEYBALL (FIVB). Almeria: the start of a new age. FIVB Magazine, Lausane, 1993.

FIORENTINO, A. La historia del beach voley em el año de su debut olimpico. Revista Voley, Buenos Aires, v. 26, n. 83, abr./mai. 1996.

\section{GOOD NEWS. Revista Volei de Praia, São}

Paulo, ano III, n. 7, 1993.

HISTORY OF BEACH VOLLEYBALL. Disponível em:<http://www.volleyball.org/history beach.html> . Acesso em: 12 jan. 2011.

HOBSBAWM, E. Era dos extremos: o breve século XX: 1914-1991. São Paulo: Companhia das Letras, 1995.

KASZNAR, I. K.; GRAÇA FILHO, A. Estratégia empresarial: modelo de gestão vitorioso e inovador da Confederação Brasileira de Voleibol. São Paulo: M.Books, 2006.

MARCHI JÚNIOR, W. "Sacando” o voleibol. São Paulo: Hucitec, 2004.

NUNES, J. P. Mundial de praia vai começar. 0 Estado de S. Paulo, São Paulo, 15 fev. 1987. Caderno Esportes, p. 44.

SHEWMAN, B. Volleyball centenial: the first 100 years. Indianapolis: Master Press, 1995.

SMITH, S.; FEINEMAN, N. Kings of the beach: the story of beach volleyball. Los Angeles: Power Books, 1988.

VOLLEYBALL WORLD WIDE. History of Beach Volleyball. Disponível em:<http://www.volleyball.org/history beach.html> . Acesso em: 11 dez. 2003.

WEBER, M. A ética protestante e o espírito do capitalismo. São Paulo: Pioneira, 1967.
Endereço:

Gilmar Francisco Afonso

R. Dep. Mário de Barros, 833/106 Centro Cívico Curitiba PR Brasil

80530-280

Fone: (41) 3252.1591

e-mail: gilmar.afonso@pucpr.br

Recebido em: 7 de agosto de 2010. Aceito em: 29 de setembro de 2011.

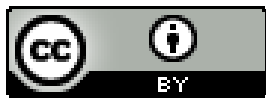

Motriz. Revista de Educação Física. UNESP, Rio Claro, SP, Brasil - elSSN: 1980-6574 - está licenciada sob Creative Commons - Atribuição 3.0 